\title{
PENAMPILAN VEGETATIF DAN GENERATIF 10 GENOTIF GANDUM (Triticum aestivum L.) DENGAN VARIETAS KONTROL GURI-3 DI DATARAN MENENGAH, KELURAHAN BLOTONGAN, KECAMATAN SIDOREJO, KOTA SALATIGA, PROVINSI JAWA TENGAH
}

\author{
${ }^{1}$ Pedro Jacob Bosco Amaral, ${ }^{2}$ Ir. Djoko Murdono, M.S. \\ ${ }^{1}$ Agroekoteknologi, Fakultas Pertanian Dan Bisnis, Universitas Kristen Satya Wacana
}

\begin{abstract}
Research on vegetative and generative appearance of 10 wheat (Triticum aestivum L.) genotives was conducted in June 2017 until September 2017 in Blotongan Area, District Sidorejo, Salatiga which has a height of $\pm 698 \mathrm{~m}$ above sea level. The purpose of this study was to determine and obtain the appearance of vegetative and generative 10 genotypes of wheat that grow well in the plains medium. This research is using the RAK and analysis of variance with test HSD 5\%. The treatments were 10 genotypes, namely: FUNDACEP 30, Filin / $2 * 1 P A S T A R 11$ QUAIU, WBLL * 2KURUKU, PRL / 2 * PASTOR, Pfau / MILAN / 3 / SKAUZ / KS9, KIRITATI / 4/2 / * SERI.1B * 2, TRCH * 2/3 /C80.I/3, SAAR / 2 / WAXWING, GURI 3. The treatment is repeated 3 times. The results showed that there is a difference in the appearance of vegetative between genotives tested in terms of plant height and number of leaves. While the number of tillers, flowering age, and harvest age is no different. On the appearance of the generative found no difference between genotives in terms of the number of seeds per panicle, seed weight per $m^{2}$, the middle row 4th seed weight, seed weight per panicle, and the weight of 1000 seeds. While the length of spikelet number of panicle and seed weight of 1 liter is not unlike real; Genotif that has levels of appearance of vegetative and generative in the Middle Plains is PRL/2*PASTOR and TRCH* 2/3/C80. I/3 relatively better than the varieties of Guri-3 as control varieties; Factors temperature, drought, soil $\mathrm{pH}$, and soil texture when testing are causing high stress, so that the appearance of Guri-3 as control varieties haven't been able to emulate the appearance according to the description of the varieties of Guri-3.
\end{abstract}

Keywords: Genotive, Appearance, Vegetative, Generative, Middle Plain

\section{PENDAHULUAN}

Gandum (Triticum aestivum L.) adalah salah satu serealia dari famili Gramineae (Poaceae). Gandum merupakan salah satu bahan makanan pokok, karena mengandung gluten dan proteinnya yang cukup tinggi. (Asosiasi Produsen Tepung Terigu Indonesia/APTINDO, 2009). Tanaman gandum sebenarnya jarang ditemukan di Indonesia dengan alasan kondisi lingkungan fisik di Indonesia tidak sesuai untuk budidaya tanaman gandum karena merupakan tanaman subtropis, namun tanaman ini dapat tumbuh dengan baik di daerah tropis dengan ketinggian >800 m dpl (Handoko, 2007), dengan curah hujan sekitar $139 \mathrm{~mm}$ per tahun (Sunet al., 2006). Akan tetapi, budidaya gandum pada dataran tinggi kurang ekonomis karena bersaing dengan komoditas hortikultura. tetapi masyarakat Indonesia cenderung lebih menyukai produk olahan gandum seperti mie instan bahkan lebih besar dari jagung dan ubi kayu (Haryanto et al.,2002). Kevin (2013), menyatakan bahwa konsumsi gandum di Indonesia sekitar 20\% dari total konsumsi pangan nasional. Akan tetapi hasil produksi gandum di Indonesia sendiri belum mencukupi permintaan 
konsumen atau pelanggan, sehingga alternatif yang digunakan adalah melakukan pengimporan gandum dari negara lain. Halhal yang menjadi kendala dalam budidaya tanaman gandum di Indonesia adalah dimata masyarakat tentang tanaman gandum tidak cocok ditumbuhkan di daerah tropis alasannya karena lingkungannya tidak mendukung. Berdasarkan latar belakang yang ada diatas maka perlu dilakukan penelitian untuk mendapatkan genotip gandum yang mampu tumbuh dengan baik dan berproduksi tinggi pada dataran menengah. Maka penelitian ini bertujuan untuk mengetahui penampilan vegetatif dan generatif dari 10 genotip galur gandum didataran menengah. dan mendapatkan genotif atau galur gandum yang memiliki tingkat penampilan vegetatif dan generatif yang baik di dataran menengah.

\section{METODOLOGI PENELITIAN}

\section{Waktu dan Tempat Penelitian}

Penelitian ini dilaksanakan pada tanggal 23 Juni 2017 sampai bulan September 2017 yaitu mulai dari pengolahan tanah sampai panen yang bertempat di kampus baru FTI

\section{Pengamatan Selintas}

Tabel 4.1. Tabel Analisa Kandungan Bahan Organik Tanah dan Fraksi-fraksi tanah

\begin{tabular}{llllllll}
\hline Sampel & KA & BO(abs) & BO(\%) & BO(gr) & \%PASIR & \%LIAT & \%DEBU \\
& & & & & & & \\
\hline (I) & 3.99 & 0.02 & 0.38 & 0.37 & 2.20 & 40.28 & 57.52 \\
(II) & 4.01 & 0.02 & 0.38 & 0.37 & 0.61 & 41.76 & 57.63 \\
\hline
\end{tabular}

Keterangan: tanah bertekstur liat berdebu diterapkan dalam segitiga tekstur tanah. 
Tabel 4.1. Bahan organik tanah sebelum pelaksanaan penelitian berkisar 0,38\%, pH tanah 7,9-8, kadar air tanah selama penelitian antara $1-3,8 \%$.

Tabel 4.2. menunjukkan bahwa Total curah hujan selama penelitian ini berlangsun (Juli 2017- Oktober 2017) adalah $374.0 \mathrm{~mm}$ serta temperaturnya berkisar antara $30.1^{\circ} \mathrm{C}-$ 19.37 C.(BMKG Semarang 2017), Simanjuntak (2002) menyatakan bahwa, tanaman gandum dapat bertumbuh dengan baik pada curah hujan $350 \mathrm{~mm}$ - $1250 \mathrm{~mm}$ selama siklus hidupnya. Menurut Fisher dan Goldsworthy (1992), tanaman gandum akan tumbuh dan menghasilkan hasil yang optimal pada suhu sekitar $10{ }^{\circ} \mathrm{C}-25^{\circ} \mathrm{C}$. Sudarmini (2001) menyatakan bahwa suhu minimum gandum adalah $2-4^{\circ} \mathrm{C}$, suhu optimumnya 20 $25^{\circ} \mathrm{C}$, sedangkan suhu maksimumnya adalah $37^{\circ} \mathrm{C}$.Gusmayanti (2000) menyatakan bahwa suhu minimum gandum adalah $5^{\circ} \mathrm{C}$ dan suhu maksimumnya adalah $37^{\circ} \mathrm{C}$.

Tabel 4.2. Data Curah Hujan

\begin{tabular}{ccccc}
\hline \multirow{2}{*}{ Bulan } & \multicolumn{2}{c}{ Suhu $\left({ }^{\circ} \mathrm{C}\right)$} & $\begin{array}{c}\text { Curah hujan } \\
\text { mm/bulan }\end{array}$ & $\begin{array}{c}\text { Jumlah hari } \\
\text { hujan }\end{array}$ \\
\cline { 2 - 4 } & Mak & Min & Rata-rata & \\
\hline Juli & 26.7 & 19.5 & 15.0 & 3 \\
Agustus & 31.5 & 17.7 & 0.0 & 0 \\
September & 32.1 & 20.2 & 101.0 & 10 \\
Oktober & 30.1 & 20.1 & 258.0 & 14 \\
\cline { 3 - 4 } & & & 374.0 & 27
\end{tabular}

Keterangan: data ini diperoleh dari BMKG Semarang Semarang (2017).

Tabel 4.3. Hasil Analisis Serangan Hama, Penyakit dan Data Persentase Tanaman Yang Hidup Pada 30 HST

\begin{tabular}{|c|c|c|c|c|}
\hline \multirow{2}{*}{$\begin{array}{l}\text { Genotip } \\
\text { G01 }\end{array}$} & \multicolumn{2}{|c|}{$\begin{array}{l}\text { Serangan Hama Penyakit } \\
\text { (jumlah lajur terserang) }\end{array}$} & \multicolumn{2}{|c|}{ \% Tanaman Yang Hidup } \\
\hline & 2.67 & $\bar{a}$ & 96.08 & $\mathrm{a}$ \\
\hline G02 & 0.00 & $\mathrm{c}$ & 91.88 & $\mathrm{a}$ \\
\hline G03 & 1.33 & $a b c$ & 98.06 & $\mathrm{a}$ \\
\hline G04 & 0.00 & $\mathrm{c}$ & 98.81 & $\mathrm{a}$ \\
\hline G05 & 0.00 & $c$ & 97.50 & $\mathrm{a}$ \\
\hline G06 & 1.00 & $\mathrm{bc}$ & 32.16 & $b$ \\
\hline G07 & 0.33 & bc & 96.03 & $\mathrm{a}$ \\
\hline G08 & 0.00 & $\mathrm{c}$ & 96.33 & $\mathrm{a}$ \\
\hline G09 & 1.67 & $a b$ & 94.27 & $\mathrm{a}$ \\
\hline G10 & 0.67 & $\mathrm{bc}$ & 92.90 & $\mathrm{a}$ \\
\hline
\end{tabular}

Keterangan. Angka yang diikuti huruf yang sama menunjukan tidak berbeda nyata sedangkan angka yang diikuti huru yang berbeda menunjukan perbedaan nyata 
Tabel 4.3. Dalam pelaksanaan penelitian ini telah diamati bahwa jenis hama yang menyerang beberapa varietas tanaman gandum atau genotip tanaman gandum yang diuji di dataran menenggah adalah hama pengerek batang(Scirpophaga inotata), belalang,pengerek akar(sundep/Termite), aphids (Leurodicus sp) dan walang sangit(Leptocorisa acuta) dan penyakit yang menyerang adalah embun jelaga,

\section{Pengamatan Utama}

Tabel 4.4Tabel Hasil Analisis Tinggi Tanaman, Jumlah Anakan, Jumlah Daun, Umur Berbunga dan Umur Panen

\begin{tabular}{lcccccccccc}
\hline Genotip & \multicolumn{2}{c}{$\begin{array}{c}\text { Tinggi } \\
\text { Tanaman }\end{array}$} & $\begin{array}{c}\text { Jumlah } \\
\text { Anakan }\end{array}$ & $\begin{array}{c}\text { Jumlah } \\
\text { Daun }\end{array}$ & $\begin{array}{c}\text { Umur } \\
\text { Berbunga }\end{array}$ & Umur Panen \\
\hline G01 & 69.35 & bc & 3.63 & a & 6.80 & c & 52.67 & a & 102.00 & a \\
G02 & 68.51 & c & 4.30 & a & 6.97 & c & 55.33 & a & 101.33 & a \\
G03 & 77.39 & a & 3.40 & a & 7.67 & a & 56.00 & a & 91.00 & a \\
G04 & 76.92 & ab & 3.90 & a & 7.60 & ab & 55.00 & a & 93.67 & a \\
G05 & 79.45 & a & 3.50 & a & 7.57 & abc & 57.67 & a & 102.00 & a \\
G06 & 78.90 & a & 5.30 & a & 7.03 & bc & 57.00 & a & 103.50 & a \\
G07 & 83.87 & a & 2.83 & a & 7.13 & abc & 58.00 & a & 97.67 & a \\
G08 & 83.75 & a & 5.30 & a & 7.63 & ab & 58.33 & a & 103.67 & a \\
G09 & 80.09 & a & 6.83 & a & 7.50 & abc & 62.33 & a & 101.67 & a \\
G10 & 81.73 & a & 6.87 & a & 7.50 & abc & 60.67 & a & 104.00 & a
\end{tabular}

Keterangan:angka yang memiliki huruf yang sama menunjukkan tidak berbeda nyata sedangkan angka yang memiliki huruf yang berbeda menunjukan berbeda nyata dengan Genotip yang lain 
Dari hasil analisis tabel 4.4 tinggi tanaman, jumlah anakan, jumlah daun, umur berbunga dan umur panen menunjukan terdapat perbedaan nyata, pada tinggi tanaman yaitu G02 yang lebih pendek dibandingkan dengan genotip lain namun genotip G04 tidak berbeda nyata dengan genotip G01, sedangkan pada jumlah daun adalah G01 dan G02 jumlah daunnya lebih sedikit dibandingkan dengan geneotip lain. Hal ini diduga bahwa genotip yang nyata lebih tinggi memiliki gen yang relatif toleran terhadap suhu tinggi dan keterbatasan air tanah seperti pada tinggi tanaman (G07) dan jumlah daun (G03) sedangkan jumlah anakan,(G06), umur berbunga (G09) dan umur panen (G10) lebih tinggi dari genotip lain namun tidak menunjukan perbedaan nyata antar genotip. Hal ini didukung oleh pernyataan (Tobing, 1987) yang menyatakan bahwa Pertumbuhan dan perkembangan tanaman gandum dipengaruhi oleh unsurunsur iklim, selain itu juga aspek tanah. Menurut hasil penelitian Firouzian (2003), diduga faktor genetik dari masing masing genotip sangat berpengaruh terhadap tinggi tanaman dibanding faktor lingkungan.).

Tabel 4.5 Hasil Analisis Panjang Malai, Jumlah Spikelet Per Malai, Jumlah Biji Per Malai

\begin{tabular}{lccccl}
\hline & Variable & \multicolumn{4}{c}{ Hasil } \\
\hline Genotip & \multicolumn{2}{c}{$\begin{array}{c}\text { Panjang Malai } \\
\text { (cm) }\end{array}$} & $\begin{array}{c}\text { Jumlah Spikelet } \\
\text { (buah) }\end{array}$ & $\begin{array}{c}\text { Jumlah biji/malai } \\
\text { (buah) }\end{array}$ \\
\hline G01 & 8.00 & $\mathrm{a}$ & $15.70 \mathrm{a}$ & $30.33 \mathrm{ab}$ \\
G02 & 8.43 & $\mathrm{a}$ & $18.50 \mathrm{a}$ & $41.60 \mathrm{a}$ \\
G03 & 8.73 & $\mathrm{a}$ & $15.77 \mathrm{a}$ & $32.17 \mathrm{ab}$ \\
G04 & 8.30 & $\mathrm{a}$ & $18.07 \mathrm{a}$ & $38.97 \mathrm{a}$ \\
G05 & 8.50 & $\mathrm{a}$ & $16.73 \mathrm{a}$ & $40.23 \mathrm{a}$ \\
G06 & 8.35 & $\mathrm{a}$ & $16.60 \mathrm{a}$ & $23.15 \mathrm{~b}$ \\
G07 & 8.00 & $\mathrm{a}$ & $16.77 \mathrm{a}$ & $36.87 \mathrm{ab}$ \\
G08 & 8.37 & $\mathrm{a}$ & $16.57 \mathrm{a}$ & $42.03 \mathrm{a}$ \\
G09 & 9.43 & $\mathrm{a}$ & $18.43 \mathrm{a}$ & $40.23 \mathrm{a}$ \\
G10 & 8.90 & $\mathrm{a}$ & $17.73 \mathrm{a}$ & $32.90 \mathrm{ab}$ \\
\hline
\end{tabular}

Keterangan: Angka yang diikuti oleh huruf yang sama menunjukkan tidak berbeda nyata

Tabel 4.5 menunjukkan bahwa tidak ada perbedaan panjang malai maupun jumlah spikelet antar genotif yang diuji. hal ini didukung oleh pernyataan Nur et al (2012), yaitu perbedaan panjang malai antar genotip lebih dipengaruhi oleh faktor genetik.Ini berarti pertanaman gandum selama penelitian sangat tercekam oleh faktor lingkungan, sehingga antar genotif tidak mampu menunjukkan perbedaan panjang malai

Jumlah biji per malai genotip G05 dan G08 nyata lebih banyak dibandingkan dengan genotip G06, dan cenderung lebih banyak daripada G10. Diduga gen pengendali kesuburan serbuksari dan kesuburan stigma maupun gen pengendali fertilisasi pada G05 
dan G08 lebih toleran terhadap cekaman suhu dan kekeringan dibanding G06, sehingga mampu menghasilkan jumlah biji yang lebih banyak daripada G06.

Tabel 4.6 Hasil Analisis Bobot Biji1M², Bobot Biji 4 Baris Tengah, bobot Biji/Malai,Bobot 1000 Biji dan Bobot Biji 1 Liter

\begin{tabular}{|c|c|c|c|c|c|c|c|c|c|c|}
\hline \multicolumn{11}{|c|}{ Variabel } \\
\hline \multirow{2}{*}{$\begin{array}{c}\begin{array}{c}\text { Genoti } \\
\mathbf{p}\end{array} \\
\text { G } 01\end{array}$} & \multicolumn{2}{|c|}{$\begin{array}{l}\text { Bobot Biji 1M } \\
\text { (gram) }\end{array}$} & \multicolumn{2}{|c|}{$\begin{array}{c}\text { Bobot Biji } 4 \text { Baris } \\
\text { Tengah (gram) }\end{array}$} & \multicolumn{2}{|c|}{$\begin{array}{c}\text { Bobot Biji Per } \\
\text { Malai } \\
\text { (gram) }\end{array}$} & \multicolumn{2}{|l|}{$\begin{array}{l}\text { Bobot 1000 } \\
\text { Biji (gram) }\end{array}$} & \multicolumn{2}{|c|}{$\begin{array}{l}\text { Bobot } 1 \text { Ltr Biji } \\
\text { (gram) }\end{array}$} \\
\hline & 107.54 & $a b$ & 207.22 & $a b$ & 10.31 & abcd & 34.27 & $b$ & 726.43 & $\mathrm{a}$ \\
\hline G 02 & 105.58 & $a b$ & 179.30 & $a b$ & 14.46 & $a b c$ & 38.48 & $a b$ & 749.49 & $\mathrm{a}$ \\
\hline G 03 & 55.20 & $\mathrm{~b}$ & 49.90 & $\mathrm{~b}$ & 11.94 & abcd & 39.25 & $a b$ & 732.6 & $\mathrm{a}$ \\
\hline G 04 & 146.03 & $a b$ & 172.12 & $a b$ & 13.05 & abcd & 34.77 & $b$ & 712.61 & $\mathrm{a}$ \\
\hline G 05 & 152.38 & $a b$ & 323.67 & $\mathrm{a}$ & 16.18 & $\mathrm{a}$ & 40.70 & $\mathrm{a}$ & 776.07 & $\mathrm{a}$ \\
\hline G 06 & 90.74 & $a b$ & 176.70 & $a b$ & 8.58 & $\mathrm{~d}$ & 38.96 & $a b$ & 706.8 & $\mathrm{a}$ \\
\hline G 07 & 69.91 & $\mathrm{~b}$ & 173.51 & $\mathrm{ab}$ & 11.42 & abcd & 36.14 & $a b$ & 758.45 & $\mathrm{a}$ \\
\hline G 08 & 169.11 & $\mathrm{a}$ & 254.35 & $\mathrm{a}$ & 13.6 & $a b c$ & 37.78 & $a b$ & 750.35 & $\mathrm{a}$ \\
\hline G 09 & 70.17 & $\mathrm{~b}$ & 54.55 & $\mathrm{~b}$ & 12.28 & abcd & 35.09 & $a b$ & 737.04 & $\mathrm{a}$ \\
\hline G 10 & 102.24 & $a b$ & 170.08 & $\mathrm{ab}$ & 11.62 & abcd & 37.65 & $a b$ & 735.31 & $\mathrm{a}$ \\
\hline
\end{tabular}

Keterangan: Angka yang diikuti oleh huruf yang sama menunjukkan tidak berbeda nyata antar perlakuan, sedangkan angka yang diikuti oleh huruf yang berbeda menunjukkan perbedaan nyata antar perlakuan.

Tabel 4.6. memperlihatkan bahwa G05 dan G08 memiliki nilai yang konsisten baik (tinggi), bahkan cenderung lebih baik (tinggi) dibanding varietas kontrol (Guri-3) dalam hal bobot biji per $\mathrm{m}^{2}$, Bobot biji 4 baris tengah, dan Bobot biji per malai. Ini berarti gen pengendali eksistensi bobot biji G05 dan G08 relatif lebih toleran menghadapi cekaman lingkungan (suhu dan ketersediaan air) dibanding genotip lainnya, sehingga mampu tampil konsisten baik.

Bobot 1000 biji dan bobot 1 liter biji menggambarkan tentang kualitas biji yang dihasilkan oleh masing-masing genotif. Tabel 4.6. menunjukkan bahwa bobot 1000 biji G05 cenderung lebih berat daripada kontrol Guri3, namun tidak beda dengan G08. Nilai heritabilitas bobot 1000 biji relatif tinggi yakni 85,70\% - 96,37\% (Firouzian, 2003). Ini berarti gen penentu bobot 1000 biji dapat diduga relatif toleran terhadap cekaman suhu dan kekeringan, sehingga mampu menunjukkan adanya perbedaan antar genotip yang diuji.

Hasil analisis menunjukkan bahwa meskipun genotip G05 memiliki bobot 1 liter biji yang relatif paling berat yang mencapai (776.07gram) dibandingkan dengan genotip lain, namun masih belum menunjukkan perbedaan nyata terhadap genotip lainnya. Ini berarti kualitas biji yang dihasilkan adalah sama berdasarkan bobot 1 liter biji. Namun berdasarkan bobot 1000 biji, maka kualitas yang kurang baik hanya pada G01 dan G04

\section{KESIMPULAN DAN SARAN}

\section{Kesimpulan}

Dari hasil dan pembahasan dapat disimpulan sebagai berikut : 
1. Ada perbedaan penampilan vegetatif antar genotif yang diuji dalam hal tinggi tanaman dan jumlah daun. Sedangkan jumlah anakan, umur berbunga dan umur panen tidak berbeda nyata. Pada penampilan generatif dijumpai ada perbedaan antar genotif dalam hal jumlah biji per malai, bobot biji per $\mathrm{m}^{2}$, bobot biji 4 baris tengah, bobot biji per malai, dan bobot 1000 biji. Sedangkan panjang malai,jumlah spikelet dan bobot 1 liter biji tidak berbeda nyata.

2. Genotif yang memiliki tingkat penampilan vegetatif dan generatif yang baik di dataran menengah adalah G05 dan G 08 yang relatif lebih baik dibanding varietas Guri3 sebagai varietas kontrol.

3. Faktor suhu, kekeringan, $\mathrm{pH}$ tanah, dan tekstur tanah ketika dilakukan pengujian sangat berpengaruh menimbulkan cekaman, sehingga penampilan Guri-3 sebagai varietas kontrol belum mampu menyamai sesuai deskripsinya.

\section{Saran}

Dari hasil penelitian ini, khususnya dari hasil dan pembahasan, dapat disarankan sebagai berikut :

1 Hasil dari ke-9 genotip tanaman gandum dan tidak termasuk varietas kontrol atau Guri-3(G10) yang diteliti didataran menenggah ini, maka perlu dilakukan penelitian ulang dari ke-9 genotip agar sala satunya atau lebih dapat direkomendasikan sebagai varietas dataran menenggah terutama pada genotip G05(PRL/2*PASTOR)dan G08(TRCH*2/3/C80.I/3).

2 Agar dapat mengetahui, pertumbuhan, perkembangan dan hasil dari ke-2 genotip tersebut yaitu genotip G05(PRL/2*PASTOR)dan G08(TRCH*2/3/C80.I/3) maka perluh dilakukan pembuktian ulang, agar kedua genotip tersebut dapat dijadikan sebagai varietas dataran menenggah.

\section{DAFTAR PUSTAKA}

Asosiasi Produsen Tepung Terigu Indonesia/APTINDO, 2009

Handoko. 2007. Gandum 2000: Penelitian Pengembangan Gandum di Indonesia. Bogor, SEAMEO BIOTROP.

Firouzian, A. 2003. Heritability and Genetic Advance of Grain Yield and its Related Traits in Wheat. Pakistan Journal of Biological Science 6(24): 2020-2023, ISSN 1028-8880. Asian Network for Scientific Information. Pakistan

Kevin, Julianto. 2013. Jerat ketergantungan Impor Gandum Mengelilingi Kita. http://politik.kompasiana.com/2013/06/ 14/jerat-ketergantungan-impor-gandummengelilingi-kita-568907.html. Diakses pada tanggal 18 April 2015.

Fisher, N. M and Goldsworhty, P. R. 1992. Fisiologi Tanaman Budidaya Tropik. Universitas Gajah Mada: Yogyakarta.

Gusmayanti, E. 2000. Penentuan Protein Pengembangan Tanaman Gandum di Indonesia. Skripsi IPB. Bogor.

Nur, A., Trikoesoemaningtyas, N. Khumaida, S. Yahya,2012. Evaluasi dan keragaman genetik 12 galur gandum introduksi di 
lingkungan tropika basah. J.Agrivigor 11:230-243.

Hariyanto, A.E, Y. Sugito, A. Soegianto. 2002. Respon Tanaman Gandum (Triticum aestivum L.) Galur Nias dan DWR 162 terhadap Pemberian Pupuk Kandang Ayam. Agrivita. 24(1): 30-36.

Tobing B.L. 1987. Pengaruh Status Air Tanah terhadap Pertumbuhan dan Hasil Tanaman Gandum. Skripsi J.G dan M. Fakultas MIFA. IPB. Bogor.

Simanjuntak, B., H. 2002. Prospek Pengembangan Gandum di Indonesia. Fakultas Pertanian dan Bisnis Universitas Kristen Satya Wacana. Salatiga. 